\title{
PLATAFORMA LOGÍSTICA NO VALE DO RIO PARDO
}

\section{ARTIGO ORIGINAL}

NASCIMENTO, Rafael Augusto ${ }^{1}$

WELSER, Leticia ${ }^{2}$

NASCIMENTO, Rafael Augusto. WELSER, Leticia. Plataforma logística no Vale do Rio Pardo. Revista Científica Multidisciplinar Núcleo do Conhecimento. Ano 04, Ed. 10, Vol. 07, pp. 174-189. Outubro de 2019. ISSN: 2448-0959, Link de acesso: https://www.nucleodoconhecimento.com.br/administracao/plataformalogistica

\section{RESUMO}

A realidade atual do mercado mostra o quanto é necessário estar em constante inovação, assim como a logística, que representa grande importância para as empresas como vantagem competitiva. Além de tornar o transporte e a armazenagem mais eficazes, uma Plataforma Logística $(\mathrm{PL})$ tem o poder de interagir no ambiente social e econômico da região, contendo a participação das iniciativas pública e privada no projeto, execução e participação, assim alavancando o desenvolvimento regional da cidade. $O$ artigo busca analisar os fatores que podem tornar possível a inserção de uma PL em Santa Cruz do Sul. Por ser um município com modais de transporte prédispostos dentro dos limites territoriais, e com característica de operação atuante em empresas que praticam multimodalidade e intermodalidade de transporte, a implantação deste centro logístico torna a região mais atrativa. Assim, conclui-se que

${ }^{1}$ Especialista em Logística e Administração (UNINTER) e Tecnólogo em Logística (UNINTER).

${ }^{2}$ Mestranda do Programa de Pós-graduação Mestrado e Doutorado em Promoção da Saúde; Especialista em Personal Training (UNINTER); Bacharel em Educação Física (UNISC). 
Santa Cruz do Sul/RS se encaixa dentro dos aspectos vistos como fundamentais para a iniciação de uma PL.

Palavras-Chave: Plataforma logística, vantagem competitiva, Vale do Rio Pardo, operador logístico, Santa Cruz do Sul.

\section{INTRODUÇÃO}

No cenário globalizado deste século, uma região economicamente rica nos setores agrícola e industrial tem como principal vantagem competitiva a sua posição geográfica, um fator decisivo para transportar e armazenar matéria prima e outros produtos. Não é possível determinar ao certo quando foi criado o primeiro equipamento de transporte, entretanto, há indícios de que coincide com o período histórico em que o homem evolui da condição nômade e começa a se fixar em determinadas regiões, com isso sente a necessidade de transportar suas provisões para a sua sobrevivência (RAZOLLINI FILHO, 2011).

A logística vem sendo praticada há séculos, de forma organizada, principalmente no contexto militar, e a história está escrita sobre casos de como linhas de suprimentos logísticos, ou a ausência delas, tornaram possíveis as campanhas de Alexandre, o Grande, Gêngis Khan e Napoleão (GRANT, 2013). Desse modo, a logística pode ser definida como o trabalho de armazenar e distribuir o estoque ao longo dos elos de uma cadeia de abastecimento. É a combinação da gestão de pedidos, da organização do estoque, do processo de transporte, da movimentação na armazenagem e da embalagem de uma empresa, integrando uma rede complexa de instalações (BOWERSOX; CLOSS; COOPER, 2007).

A partir deste pressuposto, este estudo tem por objetivo abordar a possibilidade da inserção de uma PL no Vale do Rio Pardo.

\section{METODOLOGIA}

A pesquisa usa o resgate histórico para auxiliar no método de estudo de caso sobre PLs, pois segundo Gaya e colaboradores (2008, p.105) "o estudo de caso caracteriza- 
se como uma investigação intensiva que se empenha em atingir a compreensão da singularidade de um fenômeno". Dessa forma, o estudo de caso é capaz de gerar hipóteses, diagnosticar situações e tem a capacidade de apontar indicadores que possam subsidiar assessoramentos diversos.

\section{PLATAFORMA LOGÍSTICA E CARACTERÍSTICAS POLÍTICAS, GEOGRÁFICAS E SÓCIO ECONÔMICAS EM SUA IMPLANTAÇÃO}

Uma Plataforma Logística $(\mathrm{PL})$ diz respeito a uma infraestrutura logística com multimodalidade, atendendo à prática de intermodalidade, dispositivos de telecomunicações, infraestrutura de Tecnologia da Informação (TI) e suporte comercial. Para tanto, é necessária uma região estruturada e adaptada, com o estudo regional do local, a análise econômica e do impacto que terá na região, para conseguir atender de forma eficaz aos seus usuários. A criação das PLs permeia a distribuição equilibrada de atividades econômicas na região à qual está inserida, com base em um plano apropriado de ocupação geográfica, facilitando a distribuição da produção econômica dos grandes centros para demais regiões (RAZOLLINI FILHO, 2011).

A importância de uma PL está em viabilizar ações que tornem possível a utilização pelas organizações e crie alternativas considerando a concorrência de mercado e os componentes que envolvam a logística (SILVA, 2014).A construção de PLs no Brasil está sendo vista como um empreendimento logístico inovador e vem recebendo grande importância. As PLs são uma evolução de centros de logística integrada com real condição de obter o melhor valor dos processos que envolvem as cadeias de suprimentos. Este sistema de arranjos logísticos tem fundamental importância no resultado das movimentações logísticas no país (SILVA et al, 2013).

Atualmente, o termo PL é relevante no âmbito das organizações privadas e públicas, pois as pesquisas mostram ser necessária a reformulação logística para atender de melhor forma a demanda da distribuição de produtos em centros urbanos e também responder de forma eficiente e dinâmica aos diferentes elos da cadeia de suprimentos (SILVA et al., 2014).A implementação de alternativas no sistema logístico traz aumentos competitivos, por que possibilitam, pela integração dos elos das cadeias 
logísticas, o alcance de matéria-prima direto do fornecedor, passando por equipamentos e mão de obra qualificada, e uma rede de informações tecnológicas diferenciada com qualidade. Estas alternativas buscam a integração do sistema logístico no geral, como um processo gerador de vantagem competitiva, criando ações em conjunto, superando resultados, antes individuais, os quais seriam inviáveis em aspectos técnicos e financeiros (SILVA, 2014).

A junção da operação logística começa a ser entendida como uma integração de partes objetivando o alcance da máxima vantagem competitiva, criando ações em conjunto, em que os resultados adquiridos superam a atuação individual, que seria tecnicamente e financeiramente inviável. Isto acontece pelos fatores que o sistema logístico necessita, tais como: extensão dos componentes da cadeia logística, da grande variedade de serviços oferecidos, da mão-de-obra especializada e da diversidade de equipamentos nas linhas de movimentação, canais de transporte, armazenagem e demais atividades agregadas (DUARTE, 2009).

A necessidade da redução dos custos logísticos é grande, tendo em vista o fato de serem, em muitos casos, fatores que corroboram com o aumento do custo das mercadorias. Com o desenvolvimento da PL e a multimodalidade, e direcionando o escoamento de matérias primas para um único operador logístico, a estrutura irá se definir como o principal centro para o futuro da economia local, gerando vantagem competitiva e estratégias logísticas (OLIVA; TAQUES, 2015).

A necessidade de incentivo em investimentos na infraestrutura logística do país para alavancar os eixos de conexão entre modais de transporte na próxima década é fundamental para aumentar a competitividade internacional do Brasil. As parcerias entre o poder público e o poder privado são um elo de grande importância para o desenvolvimento e o crescimento das infraestruturas logísticas e economia do país. Entende-se como tendo uma correlação entre a utilização das PLs na criação de atividades logísticas intermodais acelerando o desenvolvimento socioeconômico, e tornando a região mais competitiva, visto a necessidade da exportação dos produtos para localidades diferentes do mundo a um menor custo (SILVA et al,2013). 
As PLs precisam ter uma análise não apenas como centros logísticos, mas também como fomentadoras de negócios. A administração destas instalações precisa ter vocação para empreender, preocupando-se em captar recursos de empresas preparadas e dispostas para compartilhar suas atividades e processos e, desta maneira, contribuir na busca pela redução dos custos com melhor eficiência. Neste âmbito, um segmento que vem crescendo e poderia fazer parte destas instalações seria empresas com foco na prática da logística reversa. A logística reversa incentiva um sistema de retorno de embalagens, com um fluxo bem estruturado que envolve os clientes, estimulando o reaproveitamento de matérias e peças para serem reutilizadas de várias formas. Deste modo, empresas com esta visão podem receber incentivos se operarem em PLs especializadas (CARVALHO et al, 2013).

Para a manutenção e conservação das vantagens competitivas dos processos logísticos frente a outros mercados e regiões, o governo tem grande importância nas políticas. Isso se dá pelos incentivos fiscais e subsídios, como no compromisso de manter, modernizar e ampliar as rodovias e ferrovias, agregando melhorias na prestação de serviços entre a movimentação dos produtos, redução das tarifas aduaneiras e desembaraço ágil nas vistorias alfandegárias, quando houver exportação (BASTOS et al, 2009).

Em função da diversidade de elementos que estão presentes em uma PL, os aspectos ligados à administração deste modelo de empreendimento são fundamentais para atender a expectativa de todos os participantes. Em um contexto mais abrangente, consideramos que a gestão pública aborde uma nova temática dos assuntos já estudados sobre PL, pois a gestão deste modelo de empreendimento deve estar relacionada à forma como será a hierarquização dos operadores logísticos e/ou os atores envolvidos, e também a união que será estabelecida nas relações interorganizacionais na esfera pública (SILVA et al, 2014).

$\mathrm{Na}$ Europa é comum este tipo de prática ser desenvolvida nas PLs, tendo em vista a possível administração destes empreendimentos pela iniciativa privada, pública ou, em muitos casos, pela parceria público-privada, proporcionando vantagens competitivas aos envolvidos pelo modelo participativo nas relações estabelecidas 
entre os participantes desta cadeia logística (SILVA et al, 2014).Para as PLs operarem com eficiência, na sua melhor condição, é preciso contar com tomadas de decisões eficientes e rápidas por parte do poder público. Entende se, então, como necessária a presença dos órgãos públicos, como a Receita Federal, nas instalações das PLs, para intervir em procedimentos comerciais internacionais. Dessa forma, não é o bastante apenas investir em espaços físicos, equipamentos e tecnologia se não adaptar os processos burocráticos à fim de agilizar o desembaraço aduaneiro, auxiliando na redução temporal dos ciclos nos processos logísticos (RAZOLLINI FILHO, 2011).

\section{FATORES QUE PODEM LEVAR AO SUCESSO A IMPLEMENTAÇÃO DE UMA PLATAFORMA LOGÍSTICA}

Visto que a importância de uma PL é viabilizar ações para as organizações criarem alternativas na utilização dos seus serviços, é necessário analisar os componentes logísticos existentes em uma região com pretensão de receber a $\mathrm{PL}$, como local para criação de estações aduaneiras, rodovias, centros de carga/descarga, tecnologia empregada e suas condições e localização geográfica (DUARTE, 2004).Entre as atividades logísticas e serviços desenvolvidos em uma PL estão: armazenagem, movimentação de carga, consolidação ou desconsolidação, industrialização dos produtos, etc. Nas atividades de consolidação e desconsolidação de cargas, movimentação e distribuição encontra-se a maior representatividade. Prestadores de serviços e indústrias com arranjos em um mesmo ambiente auxiliam na criação de um serviço ou produto com maior qualidade e mais eficiência, porque ocorrem sinergias e cooperações entre si. A geração de benefícios com a utilização de PLs compreende as possibilidades na realização de várias atividades de valor agregado e com integração do sistema logístico, como embalagem, consolidação, rotulagem e movimentação de cargas, promovendo sinergia entre os processos logísticos (SILVA, 2013).

No que diz respeito à implantação de uma PL multimodal em Goiás, levando em consideração análises de dados econômicos e logísticos, concentração de grandes 
empresas no estado, amplitude de serviços e produtos da PL multimodal, variedade e ótimas vias de transportes existentes, entende-se por ser mais favorável a proposta de criação de locais para locação, como por exemplo armazéns. Este modelo estratégico de aluguel imobiliário tem como base as empresas incorporadoras que arrendam do Estado estas áreas, e nestes espaços físicos constituem armazéns voltados para a locação. Um estudo de uma PL na França apontou que este formato de arrendamento mostra um menor investimento para as iniciativas pública e privada. A viabilidade de medição sobre o crescimento da PL, investindo capital para crescimento à medida da expansão destes territórios, comprova a vantagem competitiva desta técnica (GARCIA, 2015).

Uma PL com planejamento pode receber mais investimentos em estacionamentos e áreas de conveniência devido ao elevado número de pessoas que exercem atividades nas PLs, e também é necessário prever o volume de veículos de passeio e de cargas. As localizações das PLs tendencialmente são em áreas mais afastadas dos centros urbanos. Entende-se ser uma necessidade disponibilizar aos participantes uma variedade de serviços agregados, como exemplo, o autor cita a PL de Zaragoza na Espanha, em que um shopping center com serviços bancários e agencias de correio são parte integrada da PL (SILVA, 2013).

Para Carvalho e colaboradores(2013), os elementos entendidos como essenciais para uma PL ser bem sucedida são: a localização vantajosa para acesso de diferentes modais, ou uma combinação entre eles, tornando correta a escolha pelo transporte mais eficiente para determinado produto; o aproveitamento da intermodalidade para coordenar em um único movimento os diferentes transportes, otimizando com rapidez as conexões entre os modais, a redução de custos logísticos e consequentemente dispor de maior flexibilidade nas operações; o auxílio do setor público, com participação na implementação das PLs, reconhecendo o seu papel fundamental como promotor, mediador dos investimentos para a iniciação da infraestrutura e concedendo incentivos para a participação de empresas da iniciativa privada, e; a centralização da gestão, considerado fator necessário para obter controle das 
operações e análise estratégica dos empreendimentos e agentes da cadeia colaborativa.

Em um estudo de uma PL da cidade de Porto em Portugal, foi realizada uma análise sobre o fluxo de processamento de encomendas do armazém online, que identificou a possibilidade de uma reestruturação na melhoria do layout da planta. A modificação resultou na diminuição de mais de $30 \%$ de ocupação física de trabalho manual, seguido pela redução dos deslocamentos envolvendo o tempo e o processo de encomendas (ALMEIDA, 2014). Carvalho et al.(2013)trás como exemplo o case da cidade de Kalundborg, na Noruega, que define as empresas que irão se instalar na $\mathrm{PL}$ de acordo com o potencial na integração e sinergia com os demais atores da PL. Este modelo necessita de uma governança forte executando a gestão das instalações, com incentivo à formação de relações colaborativas entres os agentes.

Mesmo reconhecendo este cenário com melhorias em que empresas atuem de forma sinérgica, é indispensável transformar em operação este envolvimento entre todos os atores da cadeia colaborativa. O envolvimento de vários setores em operações conjuntas gera responsabilidades iguais de comum acordo, para beneficiar ambas as partes. Visto a adesão das empresas neste modelo de aliança, a identificação de ineficiências e o debate para geração de soluções torna eficiente a proposta entre as empresas (NETO, 2013).

Considerando a ideia da sinergia entre empresas dentro de uma $\mathrm{PL}$, um segmento próspero para abranger as instalações são os processos da logística reversa (CARVALHO et al, 2013).

Por meio de revisão da literatura, foram identificados três atributos para a inteligência destas instalações - integração das informações e dos processos, sinergia resultante da cooperação vertical e horizontal e governança - todos validados no estudo de caso. As empresas buscam aumentar sua competitividade pela redução de custo e por maior agilidade na entrega dos produtos para seus clientes. $\mathrm{O}$ trabalho mostrou que as Plataformas Logísticas Inteligentes podem contribuir com estes objetivos de diversas formas: Como agente integrador da manufatura, localizando no mesmo espaço físico dois ou mais elos de uma cadeia, Como agente consolidador, recebendo as diversas partes de um produto 
e executando a montagem final, Como agente capaz de linearizar a demanda, mantendo os produtos em armazéns a espera do momento certo para a entrega, Como agente fragmentador, separando os produtos em lotes menores para atender a demanda do mercado, Como integrador de diversos modais e obtendo escala por meio do compartilhamento de recursos, agrupamento etc (BRANSKI; LIMA JR, 2013, p. 12).

Atualmente, organizações sociais, ou PLs sociais, são disposições voltadas à práticas de marketing que executam estas ações de uma forma embrionária, limitadas à meios virtuais, o que limita o crescimento do mercado, uma vez que os produtos estão contribuindo para o aumento das campanhas ambientais, sociais e de acessível aceitação pelos consumidores. Sendo assim, a comercialização deve ser maior e mais explorada nos diversos mercados existentes. As PLs sociais dispõem de estratégias em processos internos, fazendo com que ações de marketing assumam papéis relevantes no crescimento das PL (BARBOSA, 2015).

\section{O OPERADOR LOGÍSTICO}

Com a economia em desenvolvimento nos últimos anos, a globalização e o desenvolvimento de negócios empreendedores no país, percebe-se um aumento na concorrência entre o mercado, fazendo com que as organizações busquem formas de minimizar custos, e, ao mesmo tempo, ter qualidade no atendimento para satisfazer os clientes. Uma maneira de incentivar esta prática tem sido a contratação de empresas especializadas para executar as atividades entendidas como secundárias, melhorando o custo versus benefício, dessa forma garantindo a qualidade na forma da execução (SOUZA, 2016).

Um Operador Logístico (OL) se caracteriza por ser uma empresa especializada em assumir a operacionalidade parcial ou total de determinados processos dentro da cadeia logística. Atuando no transporte interno e externo, na armazenagem de matérias primas ou insumos, no gerenciamento do processo de negociação com fornecedores, execução e movimentação de cargas, entre outras operações (RAZOLLINI FILHO, 2011). Estas são empresas que trabalham com soluções inteligentes e conseguem executar com excelência os serviços para os clientes com 
menos custos, mais qualidade e eficiência. A empresa, na condição de cliente, aplica indicadores para monitorar os serviços prestados, podendo assim identificar falhas no processo. Terceirizar as operações nas empresas se mostra ser um fator estratégico, porque pode ocorrer a transferência de algumas atividades secundárias, destinando assim mais tempo e atenção para a atividade principal da empresa, objetivando a diminuição de recursos financeiros, mão de obra e impostos (SOUZA, 2016).

Para uma empresa ser apontada como OL, ela deve efetuar, no mínimo, duas das atividades primárias da logística, por exemplo a gestão de estoques e transporte, ou armazenagem e processamento de pedidos. Efetuando apenas uma destas funções, este serviço terceirizado será apenas um prestador de serviço (RAZOLLINI FILHO, 2011).Segundo Razollini Filho (2011), os OLs podem ser classificados de acordo com os dados mostrados no quadro 1.

Quadro 1. Descrição dos tipos de operadores logísticos.

\begin{tabular}{|c|c|}
\hline $\begin{array}{l}\text { Operadores } \\
\text { baseados } \\
\text { ativos }\end{array}$ & $\begin{array}{l}\text { São características destes operadores o recurso próprio } \\
\text { no transporte, no armazenamento, recursos e } \\
\text { equipamentos tecnológicos para a realização das } \\
\text { operações logísticas. }\end{array}$ \\
\hline $\begin{array}{l}\text { Operadores } \\
\text { baseados } \\
\text { informações }\end{array}$ & $\begin{array}{l}\text { Entende se como operadores baseados em sistemas de } \\
\text { informação e capacidade analítica, procurando soluções } \\
\text { personalizadas para cada cliente. }\end{array}$ \\
\hline $\begin{array}{l}\text { Operadores de } \\
\text { amplo espectro }\end{array}$ & $\begin{array}{l}\text { São os operadores que efetuam quase todas as operações } \\
\text { logísticas, atendendo às necessidades do cliente com maior } \\
\text { proporção na realização das atividades primárias e } \\
\text { operacionais. }\end{array}$ \\
\hline $\begin{array}{l}\text { Operadores de } \\
\text { espectro limitado }\end{array}$ & $\begin{array}{l}\text { Operam em apenas algumas das atividades logísticas, pela } \\
\text { demanda específica do cliente. }\end{array}$ \\
\hline
\end{tabular}

Fonte: Razollini Filho(2011). 


\section{IMPORTÂNCIA GEOGRÁFICA E ECONÔMICA PARA A INSERÇÃO DE UMA PLATAFORMA LOGÍSTICA EM SANTA CRUZ DO SUL}

Uma área disponível com infraestrutura e localizada estrategicamente em uma região é uma vantagem estratégica para a expansão da indústria e pode atrair novos investidores. A análise geográfica da região é fundamental para o desenvolvimento das instalações da $\mathrm{PL}$, visto que as relações comerciais da região, do país e intercontinentais estão diretamente ligadas (SEVERGNINI et al, 2018).

Há a necessidade de um meio social favorável economicamente e ambientalmente atrativo (áreas de lazer, atrações turísticas, centros comerciais e culturais, rede hoteleira, restaurantes e outros) e também a importância de apresentar conexões com diferentes modais de transporte para promover a $\mathrm{PL}$, tais como ligações terrestres (modal rodoviário e ferroviário), acessos marítimos, fluviais e aéreos (DUARTE, 1999).As cidades da região do Vale do Rio Pardo, dependentes da centralidade do município de Santa Cruz do Sul, têm sua história econômica fortemente atrelada ao processo da indústria e a produção agrícola (DORNELLES, 2015).

O investimento produtivo traz benefícios ao Produto Interno Bruto (PIB), gerando empregos, renda e elevando o desenvolvimento social da região (OLIVA; TAQUES, 2015).O município de Santa Cruz do Sul tem uma grande concentração da geração de renda na região, com o setor de comércio e serviços, se igualando a grandes metrópoles nacionais no setor agropecuário (DORNELLES, 2015).

Santa Cruz do Sul está classificada como "Centro Sub Regional A", que apresentava atividades de gestão menos complexas. Mas, quando considerada a 'área de influência segundo temas específicos: agropecuária', Santa Cruz do Sul se iguala a metrópoles de terceiro nível e também a grande metrópole nacional, alocada no primeiro nível da gestão territorial. A classe de centralidade de gestão do território, do município de Santa Cruz do Sul, foi de quinto nível, que corresponde a 84 municípios equivalentes com certo grau de desenvolvimento que polarizam serviços públicos e privados (DORNELLES, 2015, p.19).

Mundialmente reconhecida como a "capital do fumo", Santa Cruz do Sul concentra no setor industrial a sua maior receita com o retorno de impostos. São aproximadamente 
600 indústrias, grande parte delas instaladas no distrito industrial, às margens da BR471 e também da BR-287, rodovias essas que cortam o município, facilitando o transporte logístico (SEVERGNINI et al, 2018).

Pode-se destacar que uma região ou cidade quando é potencialmente difundida em logística territorial, obtém mais dinamismo e proveito em seu espaço físico, e se torna fonte de interesse e alvo para investimentos, resulta em migração de empresas com potencial, elevando os efeitos da economia local, tais como aumento na produção e mais empregos para o município (BASTOS et al, 2009).No distrito industrial de Santa Cruz do Sul estão reunidas as maiores indústrias e empreendimentos da região, sendo elas as principais companhias do ramo fumageiro como Philip Morris Brasil, Universal Leaf Tabacos, Souza Cruz, JTI e ATC, e grandes indústrias de outros setores, como Xalingo, Mercur, Pionner e Metalúrgica Mor (SEVERGNINI et al, 2018).

\section{MOBILIDADE DAS RODOVIANA REGIÃO DO VALE DO RIO PARDO}

Segundo dados da Prefeitura Municipal de Santa Cruz do Sul (2018), o município está localizado no centro do estado do Rio Grande do Sul, próximo à encosta inferior da região nordeste do estado. A rodovia RSC-287, que corta o município de Santa Cruz do Sul, tem grande importância na ligação entre cidades localizadas no centro oeste do estado, como Santa Maria à cidades localizadas na região metropolitana (SEVERGNINI et al, 2018).

Conhecida como a principal ligação entre a capital do estado e a fronteira oeste, tem relevante importância no escoamento da produção do RS. A duplicação desta rodovia, projeto do Conselho Regional do Desenvolvimento (Corede/VRP), prevê um melhor tráfego entre os municípios de Candelária e Venâncio Aires. Outra rodovia que tem relevante importância para a movimentação de cargas no estado e na região do Vale do Rio Pardo é a BR-471. Esta rodovia liga a região central do estado à cidades da região sul, como Pelotas e a cidade portuária de Rio Grande (SEVERGNINI et al, 2018). 


\section{MULTIMODALIDADE E INTERMODALIDADE}

A multimodalidade pode ser descrita como a integração entre os modais de transporte. Já a intermodalidade é caracterizada pela integração da cadeia transportadora com a prática de um único prestador de serviço especializado e apenas um documento fiscal (RIBEIRO FERREIRA, 2002).O município de Rio Pardo, vizinho à Santa Cruz do Sul e pertencente ao Vale do Rio Pardo, é banhado por um dos principais rios do RS, o rio Jacuí. Mesmo com estruturas de barragens facilitando a navegação, este modal, hidroviário, de grande importância para a região no escoamento da produção agrícola do VRP e Centro Serra, não é utilizada por falta de infraestrutura (SEVERGNINI et al, 2018).

O transporte multimodal é caracterizado por movimentar cargas de forma combinada, utilizando diferentes meios de transporte, que são o rodoviário, o ferroviário, o aéreo, o duto viário e o hidroviário. Já os serviços de transporte intermodal representam a combinação de diversos meios de transporte, onde contratos diferentes são praticados unilateralmente com empresas distintas responsáveis pelo transporte. As diferenças entre as duas formas é que a multimodalidade é feita apenas por um agente que movimenta a carga por mais de um modal (BERTAGLIA, 2009).

A construção de um novo porto no município de Rio Pardo, às margens do rio Jacuí, tornará realidade a expectativa de operar através do modal hidroviário, desafogando o transporte rodoviário na região, tornando o custo mais acessível e aumentando a vantagem competitiva da operação logística. O objetivo é instalar um terminal portuário privado, com captação de investidores. Essa proposta é existe e torna viável a operacionalidade da PL com multimodalidade (SEVERGNINI et al, 2018).

A adaptação nas diferenças entre os modais de transporte prevê a redução nos custos e a ampliação da eficiência no transporte das mercadorias, tornando benéfico às qualidades individuais de cada modal. Ao escolher entre a multimodalidade ou a intermodalidade, a empresa tem como regular a forma de atuar de acordo com cada modal, necessidades e características próprias de cada produto, porque estes sistemas possibilitam maior flexibilidade na escolha do modal mais adequado no 
transporte, reduzindo custos com operações e melhorando a competência quanto à entrega do produto. Porém, para aplicação destes métodos, é fundamental projetar investimentos em infraestrutura para adequar às necessidades de cada modal (MUNHOZ et al, 2016).

Para iniciar este projeto no Rio Jacuí, uma área de aproximadamente de 100 hectares está à disposição às margens da BR-471, juntamente com a linha ferroviária que corta o município de Rio Pardo. Estimativas preveem que o porto irá absorver $80 \%$ do transporte de grãos, madeira e fumo. Levando em consideração a economia regional, outras empresas de setores de cargas granéis, agroalimentar, combustíveis, fertilizantes e minérios serão potencias usuários deste modal. A criação de uma Estação Aduaneira da Receita Federal será uma vantagem competitiva para as operações de importação e exportação das empresas instaladas na região, e tornará a região mais atrativa para novos investidores (SEVERGNINI et al, 2018).

\section{CONSIDERAÇÕES FINAIS}

As características geográficas, econômicas e industriais mostram que o município de Santa Cruz do Sul/RS tem elevada qualificação para receber uma PL, pois suas dimensões territoriais são adequadas para a construção da planta. As indústrias já instaladas no distrito industrial movimentam a maior parte da receita para o município com geração de impostos, o que mostra que o município e região já possuem uma disposição para investimentos no setor industrial, podendo assim receber novas indústrias de diversos setores, com interesses em transporte e armazenamento.

O posicionamento do município perante as rodovias estaduais e nacionais é estratégico, facilitando o trânsito entre o norte e o sul, com ligações entre asBR-471 e BR-386, e entre a fronteira oeste e a região metropolitana, ligadas pelas BR-290 e RS-287. Também conta com a possibilidade de utilização do modal hidroviário, visto que o município vizinho Rio Pardo é banhado pelo rio Jacuí, forte canal de desafogo para as rodovias e considerada uma melhor possibilidade para redução de custos com o transporte de matérias primas e semiacabadas, colaborando para a utilização de multimodalidade e intermodalidade. Desta forma, conclui-se que Santa Cruz do Sul se 
encaixa dentro dos aspectos vistos como fundamentais para a iniciação da atividade definida como plataforma logística.

\section{REFERÊNCIAS}

ALMEIDA, Catarina Aguiar Gomes de. Redesenho do layout de uma plataforma logística. 2014. 73 fls. Dissertação (Programa de pós-Graduação da Faculdade de Engenharia Industrial e Gestão - Mestrado) Universidade do Porto, Portugal, 2014.

BARBOSA, Christiane Lima. Caracterização de plataforma logística para organizações sociais. 2015. 238 fls. Tese (Programa de Pós-Graduação da Faculdade de Engenharia Civil, Arquitetura e Urbanismo - Doutorado) Universidade Estadual de Campinas, São Paulo, 2015.

BASTOS, S. Q. A. et al. Plataforma logística: estudo da viabilidade de implantação em Juíz de Fora (MG) via caracterização das mercadorias transportadas entre Minas Gerais e Rio de Janeiro. Revista de Economia, v.35, n. 1, p. 53-73, 2009.

BERTAGLIA, Paulo Roberto. Logística e gerenciamento da cadeia de abastecimento. São Paulo: Saraiva, 2009. 546 p.

BOWERSOX, D. J.; CLOSS, D. J.; COOPER, M. B. Gestão da cadeia de suprimentos e logística. Rio de Janeiro: Elsevier, 2007. 442 p.

BRANSKI, R. M.; LIMA JR., O. F. Atributos das plataformas logísticas inteligentes. Congresso de Pesquisa e Ensino em Transportes, 2015.

CARVALHO, C. C. et al. Atributos para caracterização de plataformas logísticas: estudo de casos na Espanha, Itália e Dinamarca. Revista Transportes, v. 21, n. 1, p. 23-33, 2013.

DORNELLES, Mizael. Dinâmicas territoriais na região de Santa Cruz do Sul-RS. Seminário Internacional sobre Desenvolvimento Regional, 2015. 
DUARTE, Patrícia Costa. Plataforma Logística: desenvolvimento de um mapa estratégico para medir os benefícios com sua implantação. Revista Gestão Industrial, v. 5, n. 3,p. 41-54, 2009.

DUARTE, Patrícia Costa. Visão estratégica e impactos com a implantação de uma plataforma logística. Opinião Revista de Ciências Empresariais, Políticas e Sociais, Canoas, n. 12, p. 7-12, 2004.

DUARTE, Patrícia Costa. Modelo para o desenvolvimento de plataforma logística em um terminal. Um estudo de caso na estação aduaneira do interior - Itajaí/SC. 1999. 111 fls. Dissertação (Programa de Pós-Graduação em Engenharia de Produção Centro Tecnológico - Mestrado) Universidade Federal de Santa Catarina, Santa Catarina, 1999.

GAYA, Adroaldo(org.). Ciências do movimento humano: introdução à metodologia da pesquisa. Porto Alegre: Artmed. 2008.

GARCIA, Tércio Sathler. Proposta de povoamento da plataforma logística multimodal de goiás pela relevância econômica das cadeias produtivas e aderência das atividades econômicas. 2015. 142 fls. Dissertação (Programa de Pós-Graduação em Engenharia de Produção e Sistemas - Mestrado) Pontifícia Universidade Católica de Goiás, Goiás, 2015.

GRANT, David. Gestão de logística e cadeia de suprimentos. São Paulo: Saraiva, 2013. 362 p.

MUNHOZ, A. C. et al.Vantagens e desvantagens do uso da multimodalidade e intermodalidade no segmento do agronegócio. In: VIII SINTAGRO, SIMPÓSIO NACIONAL DE TECNOLOGIA EM AGRONEGÓCIO, 2016, Jales.

NETO, AdonisMaitino. Mapeamento e melhoria de processos para uso cruzado de plataformas logísticas. 2013. 109 fls. Monografia (Escola Politécnica - Graduação) Universidade de São Paulo, São Paulo, 2013. 
OLIVA, V.; TAQUES, F. Plataforma logística multimodal: um estudo para o caso do estado de Goiás. In: XI Congresso Nacional de Excelência em Gestão, 2015, Goiás.

PREFEITURA MUNICIPAL DE SANTA CRUZ DO SUL. Apresenta informações gerais sobre a instituição.

Disponível em: <http://www.santacruz.rs.gov.br/municipio/localizacao>. Acesso em: 15 Set. 2018.

RAZOLLINI FILHO, Edelvino. Logística empresarial no Brasil: tópicos especiais. 2. ed., Curitiba: Ibpex, 2011. 215 p.

RIBEIRO, P. C. C.; FERREIRA, K. A. Logística e transportes: uma discussão sobre os modais de transportes e o panorama brasileiro. In: XXII ENCONTRO NACIONAL DE ENGENHARIA DE PRODUÇÃO, 2002, Curitiba.

SEVERGNINI, C. et al. Guia Socioeconômico do Vale Do Rio Pardo e Centro-Serra 22a edição/ junho e julho de 2018. Disponível em<http://www.gaz.com.br/arq

uivos_biblioteca/2018/07/04/GUIA_2018_1928918d86a708dd24cb7c977ff84ec7.pdf> Acesso em: 15 Set. 2018.

SILVA, JoséLuis Gomes. Inteligência logística: um estudo sobre a implantação de uma plataforma logística no sul do Estado do Tocantins. Revista ENIAC Pesquisa, v. 3, n. 2, p. 121-139, 2014.

SILVA, Rafael Mozart. Proposta de uma estrutura de indicadores de desempenho a ser utilizada na governança de plataformas logísticas. 2013. 425 fls. Tese (Programa de Pós-Graduação da Faculdade de Engenharia Civil, Arquitetura e Urbanismo Doutorado) Universidade Estadual de Campinas, São Paulo, 2013.

SILVA, R. M. et al. Plataformas Logísticas: uma abordagem sobre as tipologias e características através de uma revisão sistemática. Revista de Literatura de Transporte, v. 8, n. 1, p. 210-234, 2014.

SILVA, R. M. et al. Utilização da parceria público-privada em projetos de plataforma logística no Brasil. In: SIMPOI, 2013, Campinas. Anais... Campinas: UNICAMP. 
SILVA, R. M.; SENNA, E. T. P.; LIMA JUNIOR, O. F. Governança pública: dimensões e atributos de desempenho aplicados à governança de plataformas logísticas. Revista Alcance Eletrônica, v. 21, n. 01, p. 98-125, 2014.

SOUZA, Felipe Cubas. A importância da gestão dos contratos de transporte como ferramenta para garantir a qualidade dos serviços prestados na terceirização de operadores logísticos. 2016. 38 fls. Trabalho de conclusão (Centro de Pesquisa e PósGraduação em Administração da Universidade Federal do Paraná - Especialização) Universidade Federal do Paraná, Curitiba, 2016.

Enviado: Setembro, 2019.

Aprovado: Outubro, 2019. 